\title{
POWER FLOW ANALYSIS OF A DISTRIBUTION SYSTEM UNDER FAULT CONDITIONS
}

\section{Serhat Berat EFE}

Bitlis Eren University, Engineering Faculty, Department of Electrical and Electronics Engineering, Bitlis/Turkey, s.beratefe@gmail.com

\begin{abstract}
Power flow analysis can be described as calculations on defining characteristic properties of steady state operating situation of energy systems. This study proposes the power flow analysis of a power distribution system, under fault conditions. Three phase-to-ground faults are applied on various points of IEEE 9-bus system, which is designed under MATLAB/Simulink platform. Obtained results are compared with normal operating conditions to determine the behavior of system for transient operating conditions.
\end{abstract}

Key words: Power flow analysis, distribution system, MATLAB.

\section{Introduction}

Power flow analysis is one of the most vital study for power systems. It is necessary to perform this calculation during planning section. Power flow studies provide mathematical calculations to determine the bus voltages, phase angles, active and reactive power flows through power system components. The study gives steady state solutions of the voltages at all the buses, for a particular load condition (Kaur, G.). The main information obtained from the load flow or power flow analysis comprises magnitudes and phase angles of load bus voltages, reactive powers and voltage phase angles at generator buses, real and reactive power flows on transmission lines together with power at the reference bus (Afolabi).

Power flow calculations are performed by iterative methods. Most common power flow calculation methods are Jacobi Method, Gauss - Seidel Method, Newton - Raphson Method and Fast Decoupled Method. Among these methods, Gauss-Seidel Method is more accurate and faster method. Computer based methods used to analysis the power systems are developed instead of the steady state of mathematical methods (Efe). Solution of the network problems gets easier due to the development of computer technology. There are various studies for power flow analysis from high-voltage power systems to low-voltage distribution systems including distributed energy resources (DERs) (Souli, Abaci, Kaur, R., Terzioğlu). In this study, power flow analysis is performed for IEEE 9-bus system under fault conditions designed under MATLAB/Simulink platform. Fault points are placed at slack 
bus, PV bus and load bus. Obtained results are compared with normal operating conditions to determine both system behavior under fault conditions and most effective fault point of the system.

\section{Power Flow Study}

The main information obtained from the power flow study comprises of magnitudes and phase angles of bus voltages, real and reactive powers on transmission lines, real and reactive powers at generator buses, other variables being specified (Kaur, R.). The power flow algorithm used on balanced and three phase energy systems under steady state conditions, based on the following rules:

$\checkmark$ Generators supply all loads and total power loss of power lines. They cannot exceed their nominal active and reactive power capacities.

$\checkmark$ Voltage amplitudes of all busbars are about nominal voltage limits.

$\checkmark$ Power lines and transformers cannot overload.

In power flow analysis, characteristic values of various components such as busbars, generators, power lines and transformers are used for calculations (Efe, Jain, Müller).

\subsection{Study System}

According to the purpose of study, IEEE 9-bus system is designed under MATLAB / Simulink platform by using the values given in (Anderson). While the single line diagram of the system is given in figure 1, designed system which faults are added is given in figure 2.

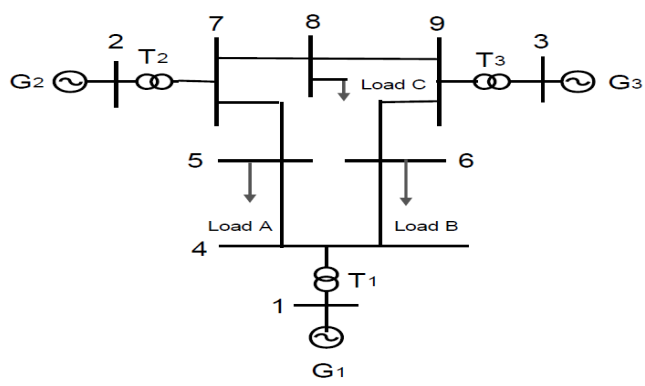

Figure 1. Single Line Equivalent of Study System 


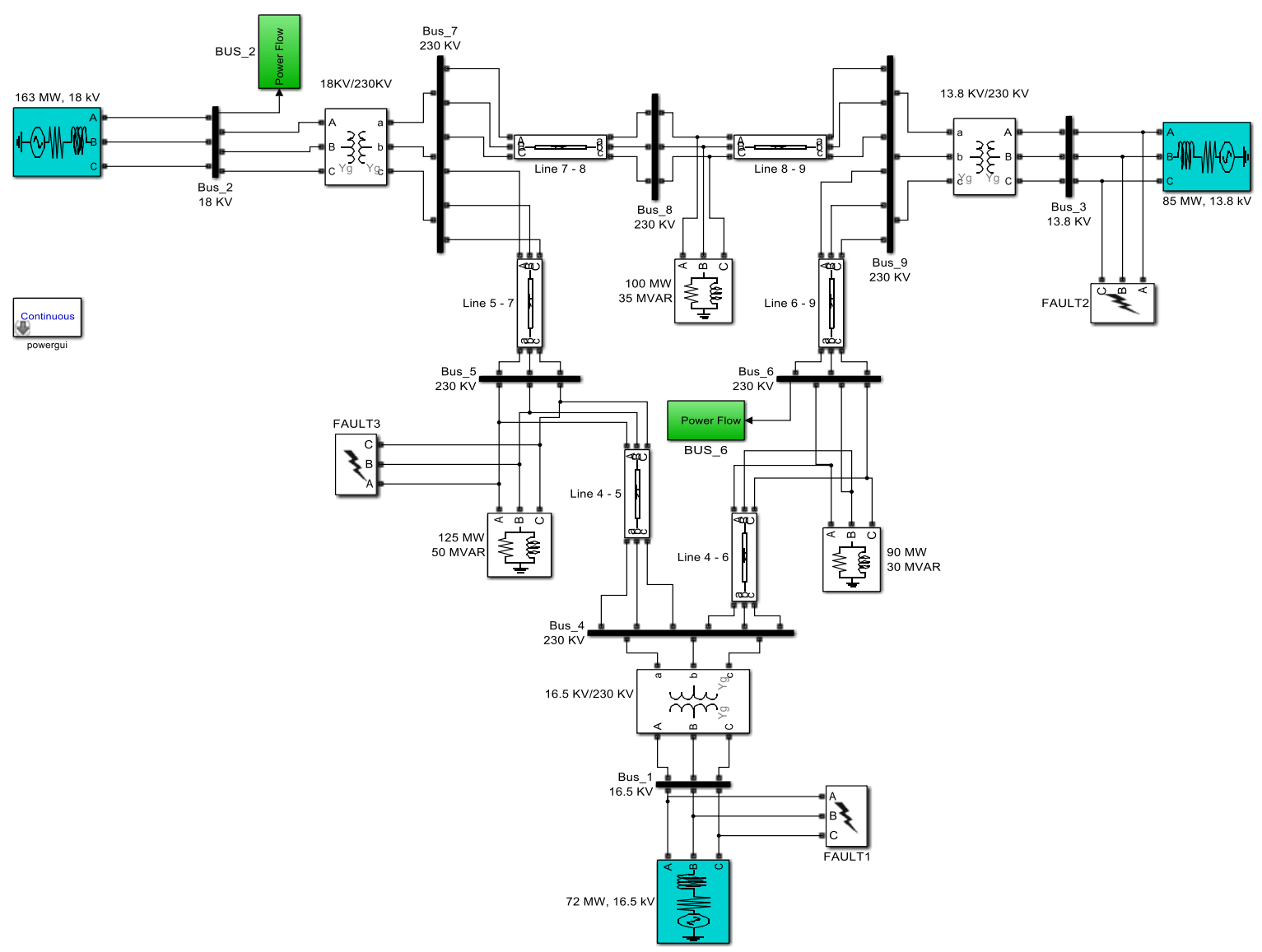

Figure 2. Designed System

Designed system is simulated and for normal operation conditions, voltage amplitude and phase angle graphs that obtained from bus 2 and bus 6 are given in figure 3 and figure 4 respectively.
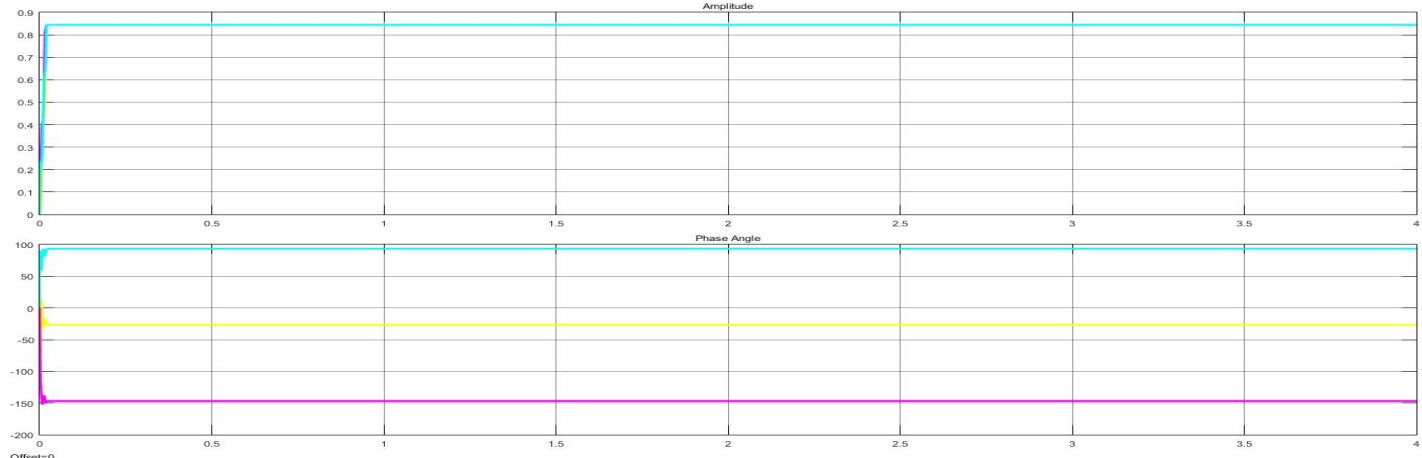

Figure 3. Amplitude and Phase Angle Graphs of Bus 2 for Normal Operating Conditions 


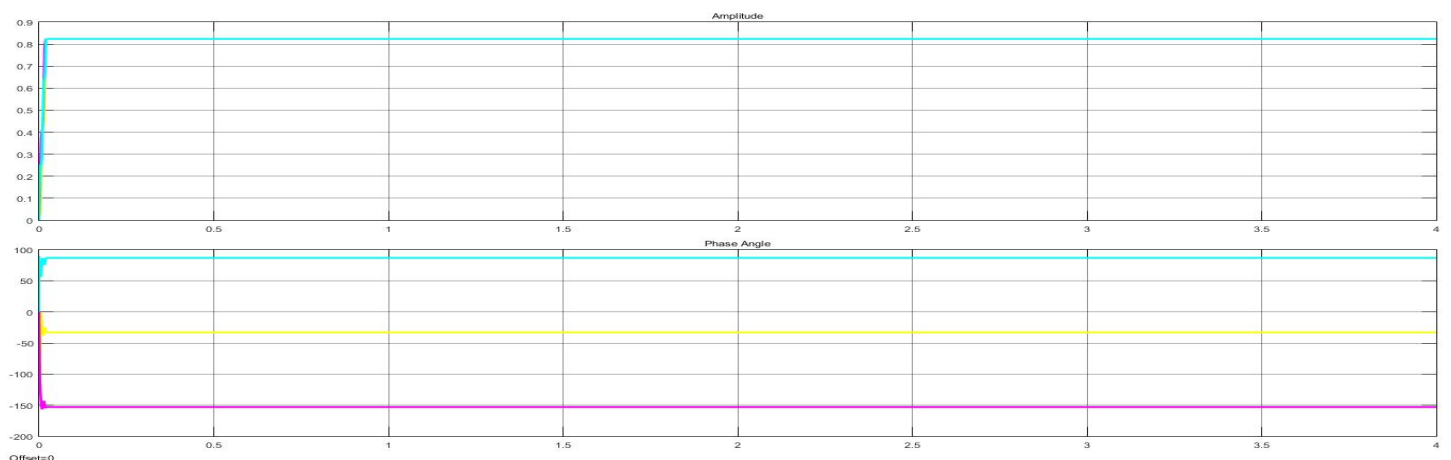

Figure 4. Amplitude and Phase Angle Graphs of Bus 6 for Normal Operating Conditions

\section{Method}

As the normal operation graphs are given above, three fault scenarios are applied on the system to determine the effects of faults on power flow parameters which are voltage amplitude and phase angle of distribution system. Fault scenarios are summarized in table 1.

Table 1. Fault Properties

\begin{tabular}{lcccc}
\hline Fault \# & Fault Type & Applied Bus & Beginning & End \\
\hline Fault 1 & Three phase to & Bus 1 & 1.0 & 1.5 \\
Fault 2 & ground & Bus 3 & 2.0 & 2.5 \\
Fault 3 & & Bus 5 & 3.0 & 3.5 \\
\hline
\end{tabular}

Simulation is performed for 4 seconds. Fault condition graphs are obtained from bus 2 and bus 6 are given in figure 5 and figure 6 respectively for comparison.

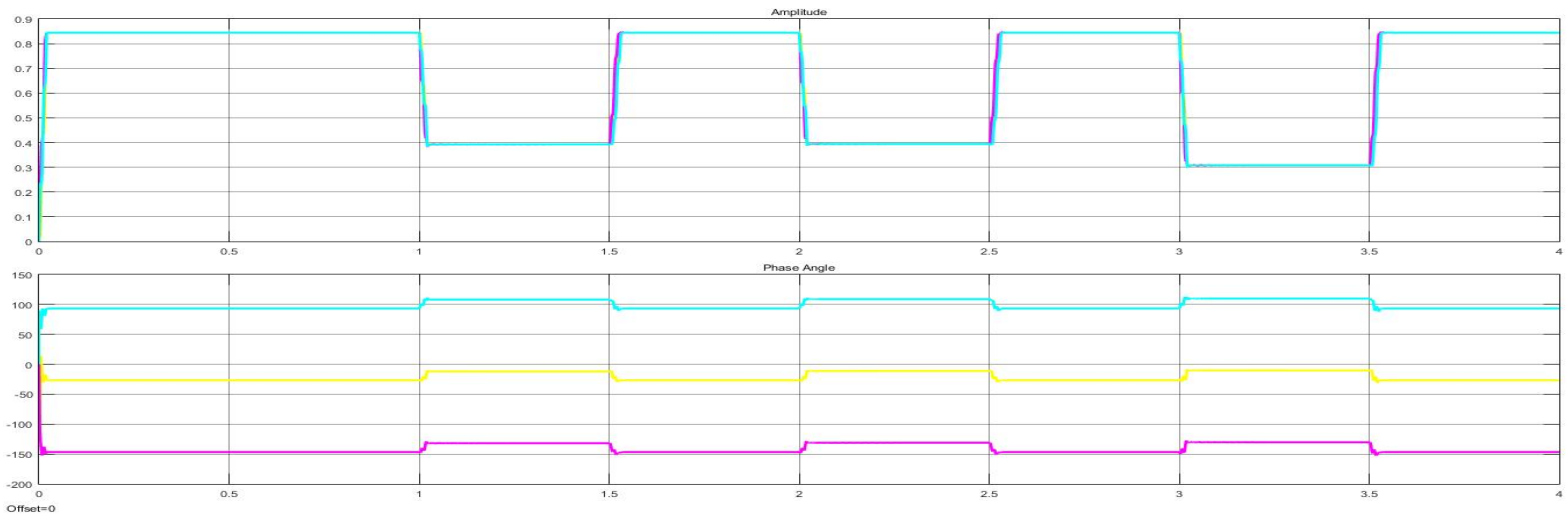

Figure 5. Amplitude and Phase Angle Graphs of Bus 2 for Fault Scenarios 


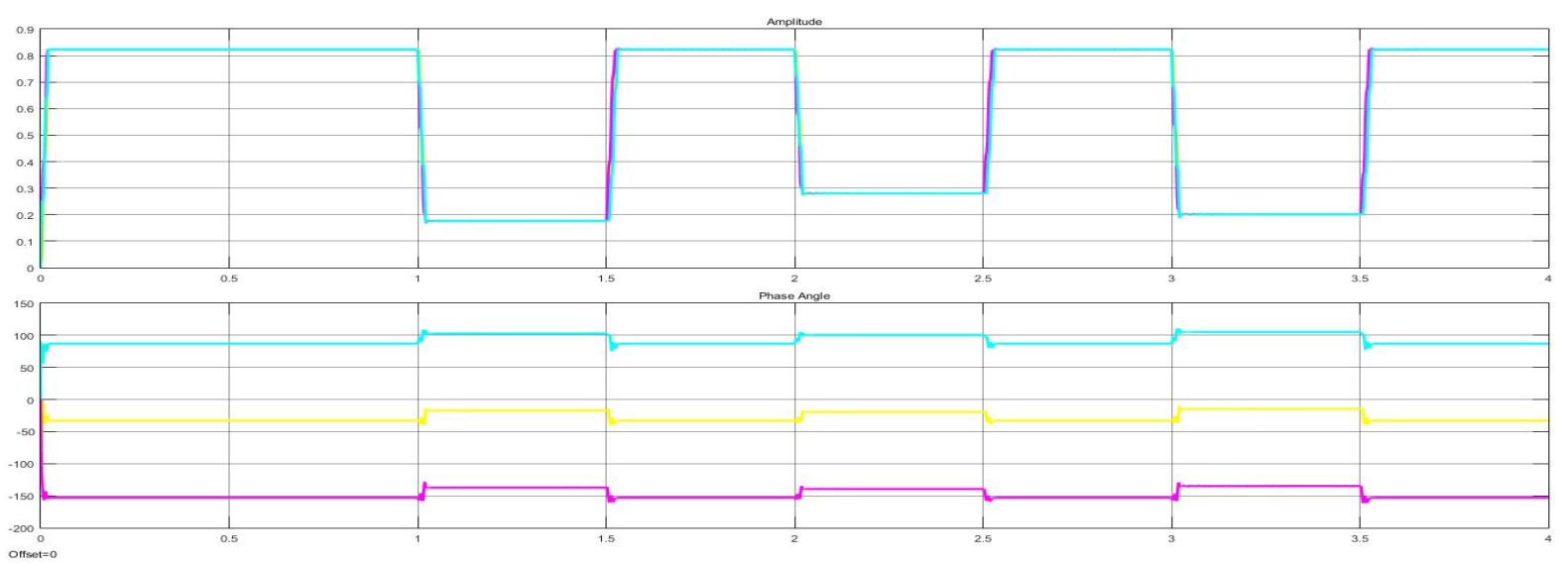

Figure 6. Amplitude and Phase Angle Graphs of Bus 6 for Fault Scenarios

\section{Results And Findings}

Fault points are placed at bus 1, bus 3 and bus 5 which are slack bus, PV bus and load bus respectively. Also measurement points are placed at bus 2 and bus 6, which are PV bus and load bus respectively to observe the effects of fault at different points of system. Findings can be summarized as follows;

Faults have more reverse effects on amplitude than phase angle.

$\checkmark$ During faults, load bus (bus 6) amplitude is decreased dramatically when compared with PV bus (bus2). While the PV bus has a minimum value of $0.32 \mathrm{pu}$ among all faults, load bus is decreased to 0.17 pu during slack bus fault.

$\checkmark \quad$ Also PV bus has minimum value during load bus fault.

$\checkmark$ Faults affect phase angles for both buses, but when figures 5 and 6 are compared, it is clear that load bus phase angle is more sensitive than PV bus phase angle.

$\checkmark$ While the load bus fault is most effective on PV bus magnitude, slack bus fault affect load bus magnitude more.

These graphs and findings validate that any fault occurs on distribution system directly affect power flow parameters and so power flow analysis calculations.

\section{Conclusion}

Power flow analysis is one of the most important calculation during both design and operating sections of a power system. So, it is necessary to consider all parameters which are possible to affect calculation results. In this study, effects of faults on power flow analysis parameters, which are voltage amplitude and phase angle, of a distribution system is investigated. IEEE 9-bus system is designed under MATLAB/Simulink platform. Three faults, which are placed at slack bus, PV bus and load bus are applied on system and results are obtained from two measurement points out of these buses, to 
determine the effects of faults on power flow analysis parameters. It is clear from graphs that it is necessary to take faults into account when performing power flow calculations for accurate results.

\section{References}

[1] Abaci, K., \& Yamacli, V., Differential search algorithm for solving multi-objective optimal power flow problem. Electrical Power and Energy Systems, 79 (2016), pp.1-10.

[2] Afolabi, O.A., Ali, W.H., Cofie, P., Fuller, J., Obiomon P., \& Kolawole, E.S., Analysis of the Load Flow Problem in Power System Planning Studies. Energy and Power Engineering, 7 (2015), pp. 509-523.

[3] Anderson, P. M., \& Fouad, A. A., Power System Control and Stability, 2nd ed. IEEE Press, New York, USA, 2003

[4] Efe, S.B., \& Cebeci, M.. Power flow analysis by Artificial Neural Network. International Journal of Energy and Power Engineering, 2 (2013), 6, pp.204-208.

[5] Jain, A.,Tripathy S.C., \& Balasubramanian R., Neural Network Based Stochastic Load Flow Analysis, Proceedings, International Conference on Power System Technology. Singapore, 2004

[6] Kaur, G., Bath, S. K., \& Sidhu, B. S., Comparative Analysis of Load Flow Computational Methods Using MATLAB. International Journal of Engineering Research \& Technology (IJERT), 3(2014), 4, pp. 2209-2219.

[7] Kaur, R., \& Kumar, D., Transient Stability Analysis of IEEE 9 Bus System in Power World Simulator. Int. Journal of Engineering Research and Applications, 6 (2016), 1, pp.35-39.

[8] Müller, H.H., \& Rider J.M., Power Flow Model Based on Artificial Neural Networks, Proceedings, IEEE Russia Powertech. St. Petersburg, Russia, 2005

[9] Souli, A., Hellal, A., Bashour, R., \& Kharaz, A.. Impact of Loads on Power Flow in Power Systems Using PowerApps and ETAP, Przeglad Elektrotechniczny, 91(2015), 7, pp. 120-123.

[10] Terzioğlu, R., \& Çavuş, T.F., Probabilistic Load Flow Analysis of the 9 Bus WSCC System. International Journal of Scientific and Research Publications, 3 (2013), 9, pp. 1-4. 